\title{
Dynamic Modelling and Simulation of a Combined-Cycle Power Plant Integration with Thermal Energy Storage
}

\author{
Decai Li, Yukun Hu, Wei He, Jihong Wang ${ }^{1}$ \\ School of Engineering, University of Warwick, Coventry, CV4 7AL, UK \\ ${ }^{1}$ Correspondence author, email: jihong.wang@warwick.ac.uk
}

\begin{abstract}
The Combined-Cycle Gas Turbine (CCGT) power plants are increasingly required to provide the service for balancing the load demand and power supply with the increase of the intermittent power generation from renewable energy sources. To ensure CCGT power plants to operate flexibly and efficiently, it is necessary to find the suitable strategy. This paper presents the feasibility of a CCGT power plant combined with the Thermal Energy Storage (TES) to improve the plant operation flexibility. The dynamic simulation models of a 420MW CCGT power plant and TES system are presented in this paper. The TES charging and discharging strategies are investigated. The simulation results show that TES charging or discharging processes provide the additional mechanisms for regulating the output power of the CCGT power plant.
\end{abstract}

Keywords-Combined-cycle gas turbine power plant; dynamic model; thermal energy storage.

\section{INTRODUCTION}

The renewable energy sources are increasingly considered for electrical power generation, which makes the instant match between power supply and load demand more challenging. The imbalance between power generation and consumption will have a significant impact on the grid stability. This leads to a role change for conventional fossil fuel thermal power plants: from base load supply to peak load generation and services. Gas turbine based power plants are flexible so they are required to operate passively with the load change, but this operation could cause three issues: low plant efficiency, low load factors, and short life time.

The key advantage of Combined-Cycle Gas Turbine (CCGT) power plant is that the efficiency is higher than the non-combined cycle gas turbine power plants, since the heat from the exhaust gas of the gas turbine is recovered via Heat Recovery Steam Generator (HRSG) to produce the steam which is then fed into steam turbines for electricity generate. This paper is using the Aspen Plus software to host CCGT power plant and TES modelling and simulation. Recently, Aspen Plus has been used for power plant design and optimization. A techno-economic analysis about integrating biomass thermal conversion with existing CCGT power plant is presented in [1] by using the software

The authors gratefully acknowledge the grant support of the UK Engineering and Physical Sciences Research Council (EPSRC, EP/K021095/1 and EP/L014211/1). The authors would like to thank the research grant support from China Nation Basic Research Program 973 (2015CB251301).The authors wish to thank the China Scholarship Council (CSC) for the financial support.
Aspen Plus. Aspen Plus also have been used for optimal design of the combination of CCGT power plant and carbon capture system $[2,3]$. The energy efficiency estimation of a Combined Heat and Power (CHP) plant using Aspen Plus is published by François [4]. However, all of these studies are based on steady state models. To assess the efficiently flexible plant operation, it is essential to present the plant dynamic behavior of variable load demand. Therefore, the core of the study is to derive the CCGT power plant dynamic model.

As presented by Benato [5], the flexible operation of CCGT power plant could guarantee the stability of gird and high profit in short term, however results in a significant reduction of the lifetime of the power plant devices. Therefore, it is important to investigate the feasible strategies to enhance the power plant flexibility and improve the efficiency and lifetime. The idea of hybrid PV system, battery and gas turbine power plant is pointed out by Afanasyeva [6], which could solve the issue of intermittent power generation of solar energy. This study is to explore the potential of a new technology: introducing Thermal Energy Storage (TES) system into thermal power plant generation processes to improve the plants dynamic performance for plant flexible operation, to smooth the gap between demand and supply, and to maximize the power plant rated load operation time periods. This paper will present the dynamic modelling of the CCGT power plant and TES, and their integration. This paper also introduces a novel method to achieve whole system dynamic simulation in Aspen Plus.

\section{Modelling OF COMBINED-CyCle GAS TuRbine POWER PLANT AND TES}

The CCGT power plant consists of the gas turbine, heat recovery steam generator, and steam turbines. A 420MW CCGT power plant dynamic model with triple levels of steam was developed in Aspen Plus, which is shown in Fig. 1.

The CCGT power plant combines two thermodynamic cycles: gas cycle and steam cycle. The choice of an appropriate physical property method is significant for the accuracy of the simulation. In this model, the PR-BM property method was chosen for the gas cycle calculation [7], and STEAMNBS property method was chosen for the water-steam cycle calculation [8]. The parameters in the measurement points when the CCGT power plant works at the rated state are listed as following: 


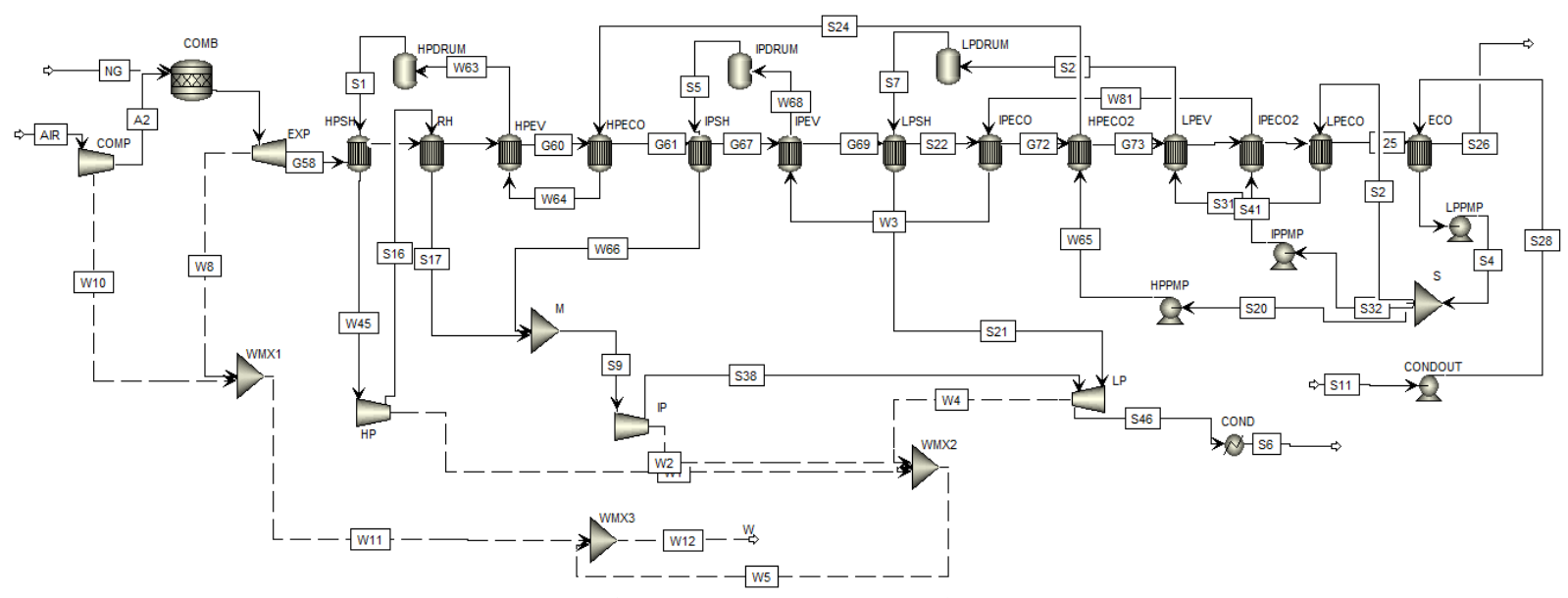

Fig. 1: 420MW CCGT power plant

- $\quad$ Gas turbine power $=284 \mathrm{MW}$

- Steam turbine power $=137 \mathrm{MW}$

- Exhaust gas mass flow rate $=685 \mathrm{~kg} / \mathrm{s}$

- Exhaust gas temperature $=859 \mathrm{~K}$

- Feed water flow rate $=108 \mathrm{~kg} / \mathrm{s}$

- High pressure steam turbine pressure $=140 \mathrm{bar}$

- Intermediate pressure steam turbine pressure $=25 \mathrm{bar}$

- Low pressure steam turbine pressure $=6 \mathrm{bar}$

In Aspen Plus, there is a function called "calculator", where the user can define a new function for the system modelling. In the calculator, there are three kinds of information flows: import variable, export variable, and tear variable. Based on tear variable, the recycle loop could be created, and then whole system dynamic simulation could be achieved.

\section{A. Gas turbine section}

The gas turbine section can be separated into three subsections: compressor, combustion chamber, and the turbine. For the compressor, the compression type is chosen as polytrophic compression, and the power requirement is calculated by [9]:

$$
\begin{gathered}
W_{\text {in }, \text { ideal }}=\left(\frac{n}{n-1}\right) P_{\text {in }} V_{\text {in }}\left[\left(\frac{P_{\text {out }}}{P_{\text {in }}}\right)^{(n-1) / n}-1\right], \\
W_{\text {in }}=\frac{W_{\text {in, ideal }}}{\eta_{c}},
\end{gathered}
$$

where, $W$ is the power, $P$ is the pressure, $V$ is the molar volume, $n$ is the polytrophic index, and $\eta_{c}$ is the compressor efficiency. The subscripts in is an inlet stream, out is the outlet stream, and ideal represents the calculation is under the ideal polytrophic conditions. The composition of air is shown in Table 1.

It is important to note that the nature gas is not $100 \%$ methane, it is composed of methane, ethane, propane, nitrogen, carbon dioxide, and so on. However, the methane and ethane account for more than $99 \%$ of the total volume [11]; therefore, only two reactions are considered in the combustion chamber:

$$
\mathrm{CH}_{4}+2 \mathrm{O}_{2}=\mathrm{CO}_{2}+2 \mathrm{H}_{2} \mathrm{O},
$$

$$
\mathrm{C}_{2} \mathrm{H}_{6}+\frac{7}{2} \mathrm{O}_{2}=2 \mathrm{CO}_{2}+3 \mathrm{H}_{2} \mathrm{O} \text {. }
$$

Table 1: The molar fraction of the air[10].

\begin{tabular}{cc}
\hline Components & Molar Fraction (\%) \\
\hline $\mathrm{N}_{2}$ & 75.67 \\
$\mathrm{O}_{2}$ & 20.35 \\
$\mathrm{H}_{2} \mathrm{O}$ & 3.03 \\
$\mathrm{CO}_{2}$ & 0.345 \\
Others & 0.915 \\
\hline
\end{tabular}

For the turbine model, the expansion type is considered as isentropic process, and the output power of the turbine is calculated by [9]:

$$
\begin{gathered}
W_{\text {out }, \text { ideal }}=-\left(\frac{k}{k-1}\right) P_{\text {in }} V_{\text {in }}\left[\left(\frac{P_{\text {out }}}{P_{\text {in }}}\right)^{(k-1) / k}-1\right], \\
W_{\text {out }}=\eta_{t} W_{\text {out }, \text { ideal }},
\end{gathered}
$$

where, $k$ is the heat capacity ratio, $\eta_{t}$ is the turbine efficiency.

\section{B. HRSG section}

Several heat exchanger models are used to develop the HRSG section. In this part, the exhaust gas from gas turbine flows into HRSG, where three levels steam (HP, IP, LP) are produced with the thermal energy from the exhaust gas. Heat exchanger dynamic model is developed based on the energy and mass balance equations. 13]:

The energy conservation equation is given by $[12$,

$$
A \rho \frac{\partial h}{\partial t}+\dot{m} \frac{\partial h}{\partial z}=\dot{Q}+W,
$$

where, $A$ is the exchange area, $\rho$ is the density of the working fluid, $h$ is the enthalpy, $\dot{m}$ is the mass flow rate, $\dot{Q}$ is the heat flux of the working fluid, $W$ is the work down on the fluid, $t$ is the time, and $z$ is the length.

Mass balance principle gives [14]:

$$
\frac{\partial \rho}{\partial t}+\frac{\partial \rho v}{\partial z}=0
$$


where, $v$ is the working fluid velocity.

The heat flux can be calculated by:

$$
\dot{Q}=U A \Delta T \text {, }
$$

where, $U$ is the heat transfer coefficient, and $\Delta T$ is the temperature difference between hot side and cold side.

In order to get the proper dynamic behavior of the heat exchanger, the heat exchanger is discretized into several cells, where the energy and mass conservation equation are applied [12], as shown in Fig. 2. The pressure is assumed as constant, therefore, the momentum balance is neglected.

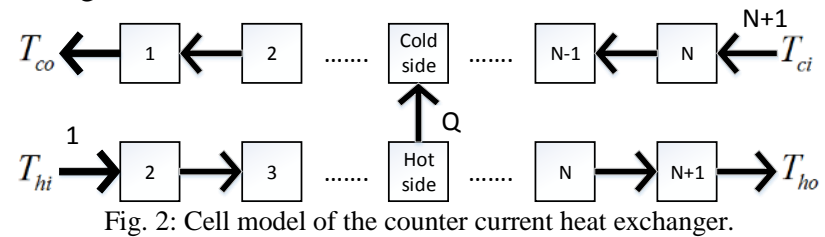

Cold side temperature change is computed by:

$$
\frac{d T_{c, i}}{d t}=\frac{U A_{i}\left(T_{h+1, i}-T_{c, i}\right)+m c_{p, c i}\left(T_{c, i+1}-T_{c, i}\right)}{V_{i} \rho c_{p, c i}}
$$

Hot side temperature change is computed by:

$$
\frac{d T_{h, i}}{d t}=\frac{-U A_{i}\left(T_{h, i}-T_{c-1, i}\right)+m c_{h, c i}\left(T_{h, i-1}-T_{h, i}\right)}{V_{i} \rho c_{p, h i}}
$$

where, $c_{p}$ is the heat capacity, subscripts $i$ represents cell $i$, the subscripts $h$ and $c$ are hot side and code side respectively.

\section{Steam turbine section}

There are three levels of steam is generated by the HRSG, which is used to spin three steam turbines: high pressure turbine (HPTB), intermediate pressure turbine (IPTB), and low pressure turbine (LPTB). The steam turbine models are based on the same thermodynamic principles which are used by the gas turbine model. The full load isentropic efficiencies are $0.88,0.88$ and 0.85 for HPTB, IPTB, and LPTB respectively, and mechanical efficiency is 0.998 . The steam turbine efficiency characteristic curve is shown in Fig. 3, it can be seen, the isentropic efficiency achieves maximum, when the steam turbine running on the rated load condition.

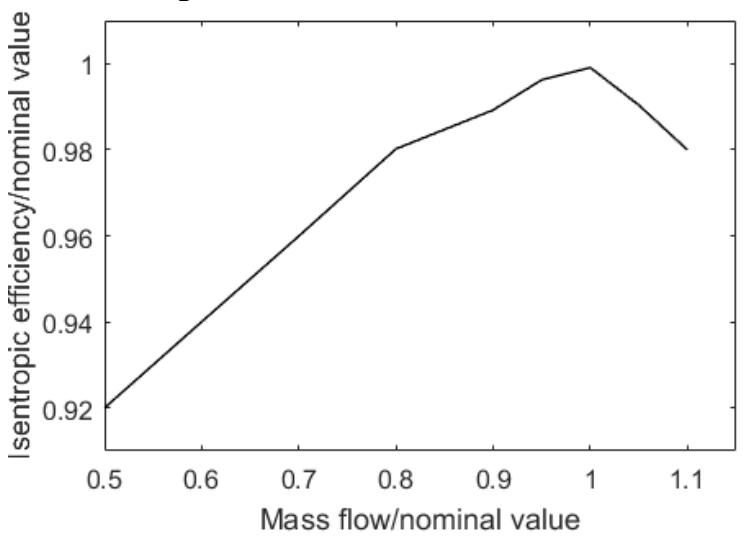

Fig. 3: Steam turbine efficiency characteristic.

\section{Thermal energy storage}

In the TES system, the thermal energy is transferred to storage media during the charging period, and released during the discharging step at the later stage. There are mainly three types of thermal energy storage, sensible heat storage, latent heat storage, and chemical heat storage [15]. The latent heat storage system will be used for this paper, due to the energy density of latent heat storage is much higher than sensible heat storage [16], and the cost is less than chemical heat storage. The NaNO3 is chose as the phase change material, and the melting temperature of NaNO3 is $580 \mathrm{~K}$ [15].

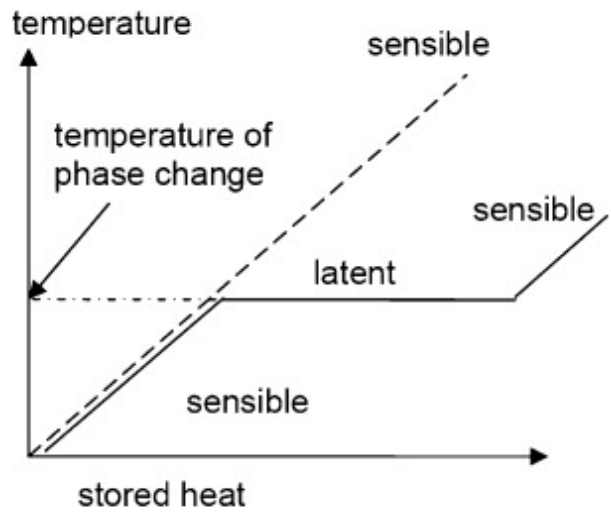

Fig. 4: Phase change Profile of PCM [17].

The structure of the TES system consists of the vessel packed in the vertical direction with cylindrical tubes, the details of the structure are presented in [18]. The model for one cylinder is shown in Fig 5 (a), it is a two concentric cylinder where the volume between them is filled with phase change material. For this TES system, there are 2500 cylinders.

In the TES system, the heat transfer process is coupled with heat convection and heat conduction. The heat transfer fluid (HTF) transfers heat to the inner side tube through heat convection. For the heat transfer from inner side tube to PCM and the thermal energy exchange inside of PCM, the heat transfer mode is heat conduction. The thermal losses through the outer cylinder of the TES are assumed negligible. A portion of a three-dimensional heat conduction grid is shown in Fig. 5 (b).

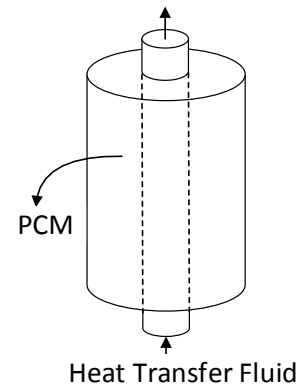

(a)

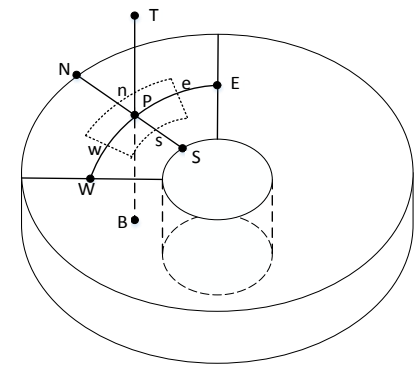

(b)
Fig. 5: (a) TES structure (b) Three dimensional heat conduction

The three-dimensional heat conduction equation in cylindrical-coordinate system is given by [19]:

$\rho c_{p} \frac{\partial T_{P}}{\partial t}=\frac{1}{r} \frac{\partial}{\partial r}\left(r k \frac{\partial T}{\partial r}\right)+\frac{1}{r} \frac{\partial}{\partial \theta}\left(\frac{k}{r} \frac{\partial T}{\partial \theta}\right)+\frac{\partial}{\partial z}\left(k \frac{\partial T}{\partial z}\right)$, 


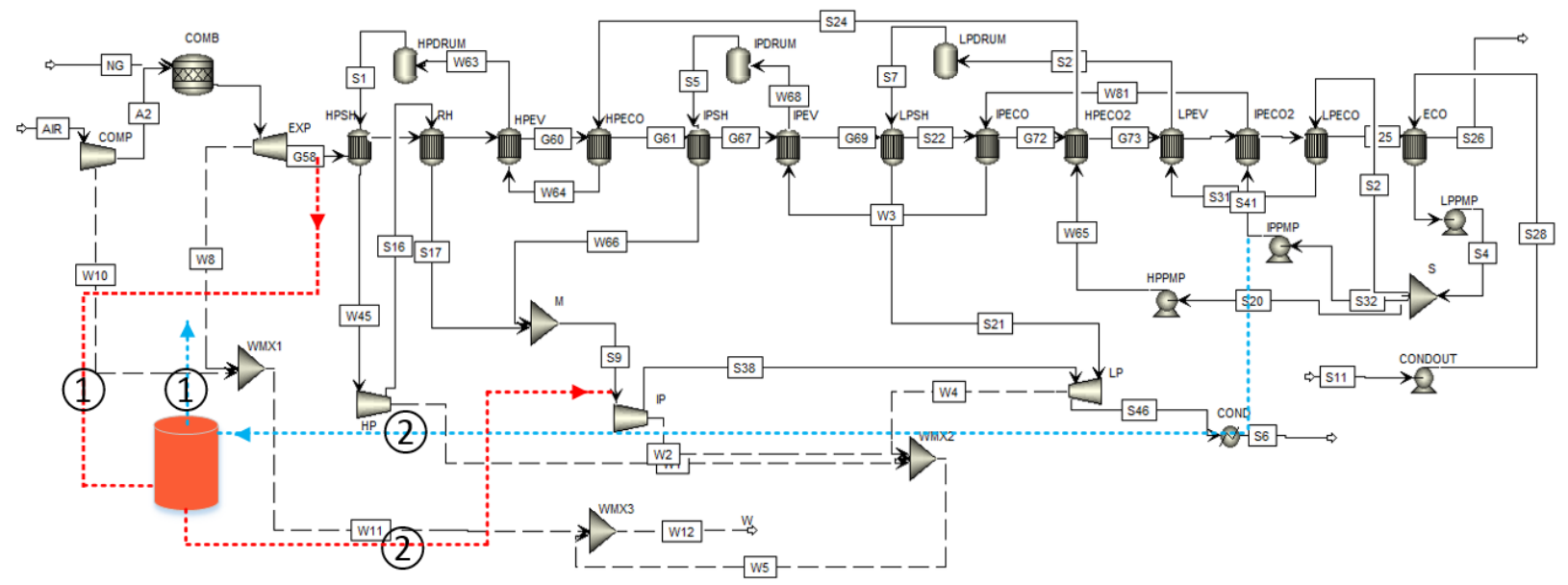

Fig. 6: TES charging and discharging strategies

where, $r$ is radius, $\theta$ is angle, $z$ is height, and $k$ is the heat-conduction coefficient, and the subscript $P$ represents point $P$. Due to this cylinder is a symmetric system, the unique temperature in $\theta$ direction are assumed. Therefore, the heat conduction equation for this cylinder is given by [20]:

$$
\rho c_{p} \frac{\partial T_{P}}{\partial t}=\frac{1}{r} \frac{\partial}{\partial r}\left(r k \frac{\partial T}{\partial r}\right)+\frac{\partial}{\partial z}\left(k \frac{\partial T}{\partial z}\right) .
$$

During the phase changing, the temperature of PCM maintains at melting temperature, and the thermal energy will be stored as the latent heat, as shown in Fig. 4, and then the enthalpy of the PCM is calculated by [15]:

$$
\rho \frac{\partial H_{P}}{\partial t}=\frac{1}{r} \frac{\partial}{\partial r}\left(r k \frac{\partial T}{\partial r}\right)+\frac{\partial}{\partial z}\left(k \frac{\partial T}{\partial z}\right),
$$

where, $H$ is the enthalpy.

\section{CCGT POWER PLANT MODEL VALIDATION}

The experimental data were collected from an operating CCGT power plant, which is presented in [21], and these data are used for model validation. The specifications of this CCGT power plant are shown in Table 2.

\section{Table 2: Power plant specifications}

\begin{tabular}{cc}
\hline Number of gas turbine & 2 \\
Gas turbine power rating & $280 \mathrm{MW}$ \\
Steam turbine & $320 \mathrm{MW}$ \\
\hline
\end{tabular}

Some test data for different operating conditions are presented in [21], and the output power of the plant for two step changes are used for model validation. For the developed CCGT power plant model, the total capacity is $420 \mathrm{MW}$, and the gas turbine capacity is $280 \mathrm{MW}$. For the test CCGT power plant, there are two gas turbines and the capacity of each of them is $280 \mathrm{MW}$.

Fig. 7 shows the CCGT power plant output power during the load increment. Fig. 8 shows the power plant output power during the load reduction. The black dash line is the simulation power, and the red circle is the experimental power from [21].

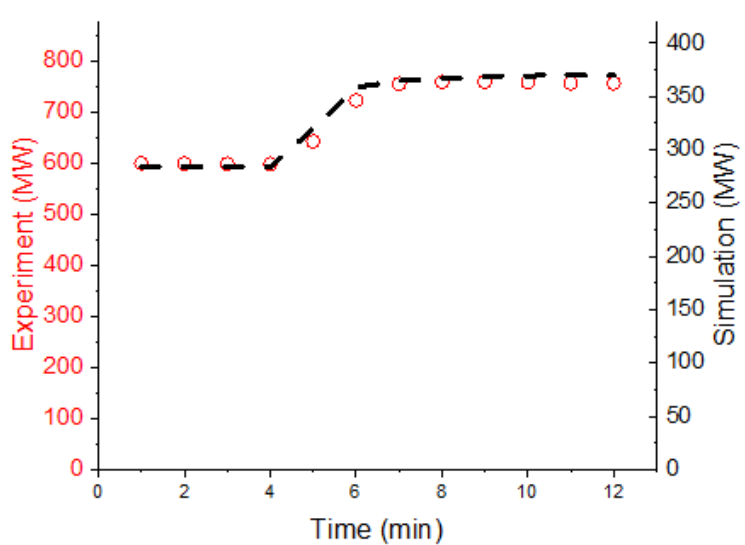

Fig. 7: Power output increase

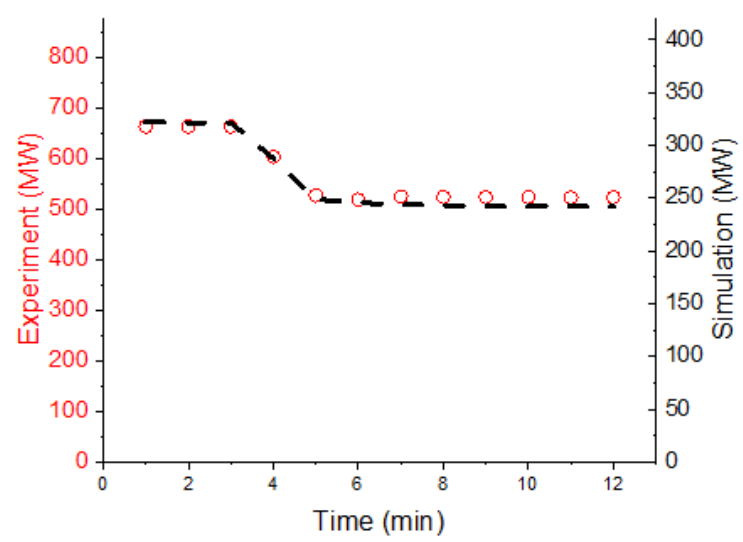

Fig. 8: Power output decrease

\section{CCGT POWER PLANT COUPLING WITH TES}

With this CCGT power plant model, the study of TES integration with CCGT power plant can be conducted. The idea of TES charging strategy is to extract part of exhaust gas from gas turbine to warm up TES during the off peak period, as shown in Fig. 6 (1), and then the steam turbine output power will decrease but the gas turbine part is still running at the rated load. This TES model is a symmetric system, therefore, one layer temperature distribution can be used to present whole cylinder temperature distribution, 
as shown in Fig. 9 (a). The initial temperature of TES is shown in Fig. 9 (b).

For the rated load condition, the mass flow rate of exhaust gas of the gas turbine is about $685 \mathrm{~kg} / \mathrm{s}$, at 100 second, $12.8 \%$ of exhaust gas $(87.7 \mathrm{~kg} / \mathrm{s})$ is extracted to charge TES. After 1000 seconds charging, the temperature of TES is shown in Figure 11. The generated power of the steam turbines decreases to about $121 \mathrm{MW}$ from $137 \mathrm{MW}$ within 8 minutes and then maintains at $121 \mathrm{MW}$, as shown in Fig. 10.

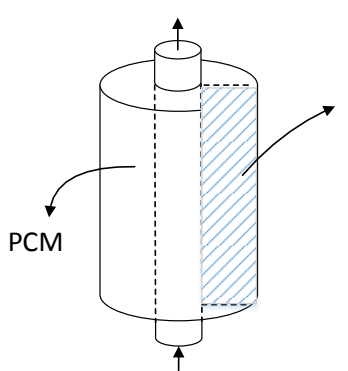

Heat Transfer Fluid

(a)

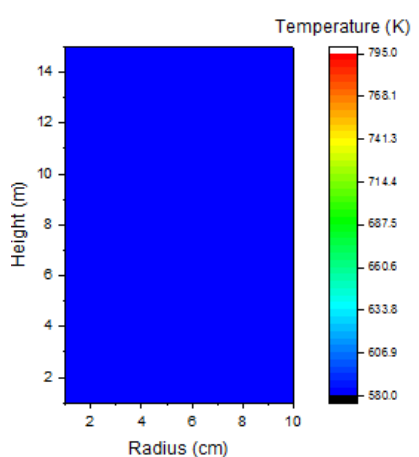

(b)
Fig. 9: (a) TES structure (b) TES initial temperature

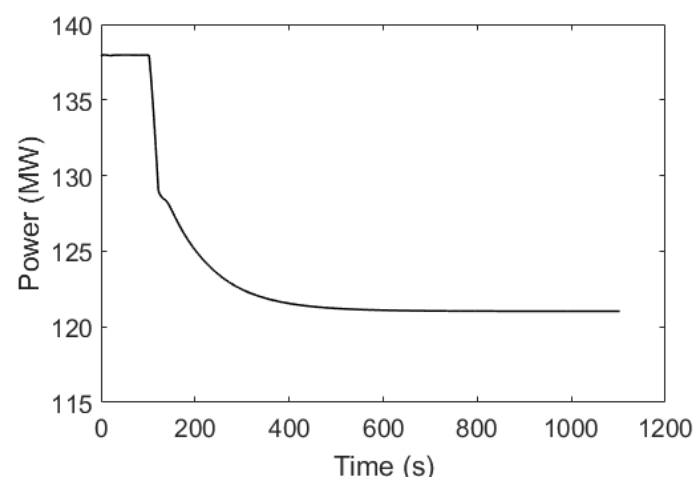

Fig. 10: Steam turbine output power

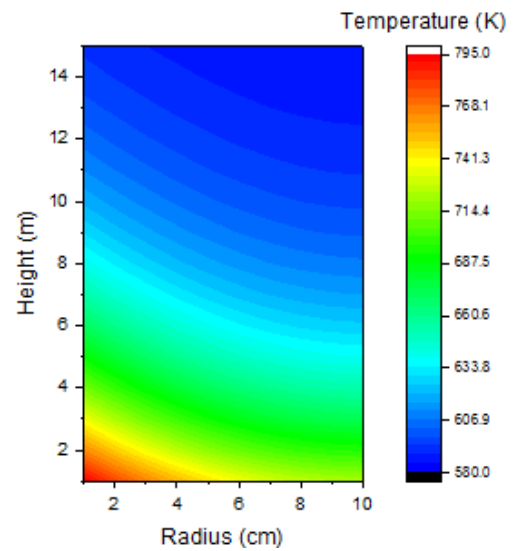

Fig. 11: TES temperature distribution after charging

After 1000 seconds charging, the TES temperature is shown in Fig. 11. In theory, the stored thermal energy should be $2700 \mathrm{MJ}$ and the real stored energy is $2695 \mathrm{MJ}$, so that the error is less than $0.2 \%$.

During the discharging process, the feed water flows into the top of TES, evaporates into high temperature steam and then leaves the TES as superheated steam, as shown in Fig. 6 (2)). Heat is transferred from TES to increase the temperature of the steam, and results in increases of electricity output. The water flow direction and the initial temperature of TES are shown in Fig. 12 (a) and (b), respectively. The initial temperature of PCM is $581 \mathrm{~K}$.

The outlet temperature of TES is shown in Fig. 13. The total generated steam is $20 \mathrm{~kg} / \mathrm{s}$, the pressure is $25 \mathrm{bar}$, and the temperature finally maintains at $580 \mathrm{~K}$, which is the melting temperature of PCM (NaNO3).

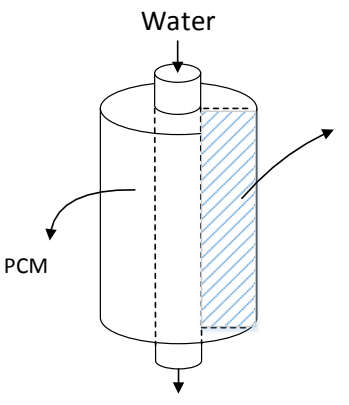

(a)

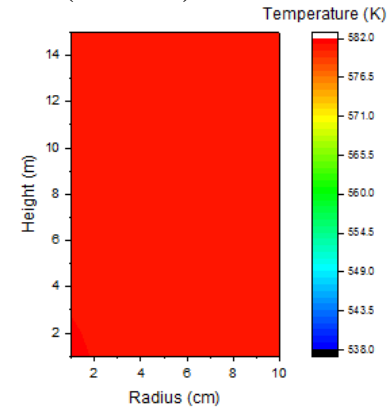

(b)
Fig. 12: (a) TES structure (b) Initial temperature

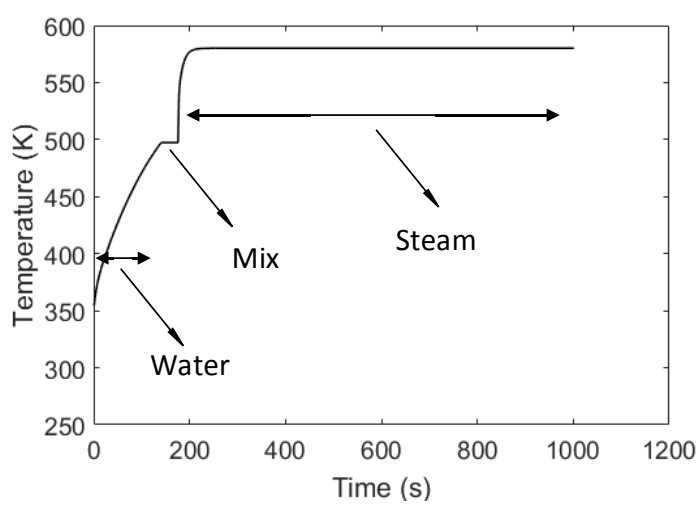

Fig. 13: Outlet steam temperature

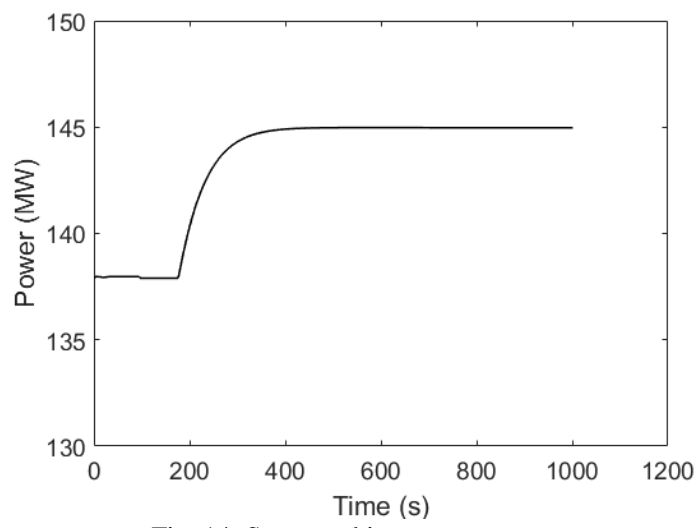

Fig. 14: Steam turbine output power

When the TES outlet is pure steam, it will be fed into IPTB to increase the output power, as shown in Fig.14. The output power of the steam turbines is increase to 145MW from 137MW. After 1000 seconds discharging, the temperature is shown in Fig. 15. It can be seen that the inner side layer of PCM is phase changing, and the PCM in the top and inner side layer is already become solid. 


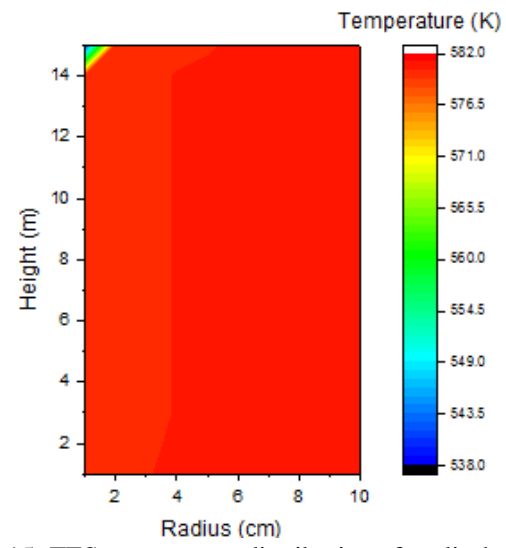

Fig. 15: TES temperature distribution after discharging

\section{CONCLUSION}

In this paper, a 420MW CCGT power plant and TES dynamic model have been developed in Aspen Plus. The developed CCGT power plant is validated by the experiment data from a real CCGT power plant, and the model presents an expected performance. The simulation results clearly indicate that it is possible to extract the exhaust gas from the gas turbine to reduce the CCGT power plant output power. The extracted exhaust gas is used to charge the TES. The stored heat will be used to generate high temperature and pressure steam for IPTB to increase the generated power. Meanwhile, the gas turbine part is still running at the rated load condition.

\section{ACKNOWLEDGMENT}

The authors would like to give our thanks to Mr. Paul Lambart from R-MC Power Recovery Ltd and Mr. Stuart Simpson from UNIPER for their valuable technical advice.

\section{REFERENCES}

[1] E. Pihl, S. Heyne, H. Thunman, and F. Johnsson, "Highly efficient electricity generation from biomass by integration and hybridization with combined cycle gas turbine (CCGT) plants for natural gas," Energy, vol. 35, pp. 4042-4052, 2010.

[2] R. Canepa and M. Wang, "Techno-economic analysis of a CO 2 capture plant integrated with a commercial scale combined cycle gas turbine (CCGT) power plant," Applied Thermal Engineering, vol. 74, pp. 10-19, 2015.

[3] A. Mathisen, H. Sørensen, M. C. Melaaen, and G.-I. Müller, "Investigation into optimal $\mathrm{CO} 2$ concentration for $\mathrm{CO} 2$ capture from aluminium production," 2013

[4] J. François, L. Abdelouahed, G. Mauviel, M. Feidt, C. Rogaume, O. Mirgaux, et al., "Estimation of the energy efficiency of a wood gasification CHP plant using Aspen Plus," Chem. Eng. Trans, vol. 29, pp. 769-774, 2012.

[5] A. Benato, S. Bracco, A. Stoppato, and A. Mirandola, "Dynamic simulation of combined cycle power plant cycling in the electricity market," Energy Conversion and Management, vol. 107, pp. 76-85, 2016. [6] S. Afanasyeva, C. Breyer, and M. Engelhard, "The Impact of Cost Dynamics of Lithium-Ion Batteries on the Economics of Hybrid PVBattery-GT Plants and the Consequences for Competitiveness of Coal and Natural Gas-Fired Power Plants," in Proceedings of the 10th International Renewable Energy Storage Conference, 2016.

[7] P. M. Mathias, H. C. Klotz, and J. M. Prausnitz, "Equation-of-state mixing rules for multicomponent mixtures: the problem of invariance," Fluid Phase Equilibria, vol. 67, pp. 31-44, 1991.

[8] W. Wagner and A. Pruß, "The IAPWS formulation 1995 for the thermodynamic properties of ordinary water substance for general and scientific use," Journal of physical and chemical reference data, vol. 31, pp. 387-535, 2002.

[9] T. Adams and N. Mac Dowell, "Off-design point modelling of a 420MW CCGT power plant integrated with an amine-based postcombustion CO 2 capture and compression process," Applied Energy, vol. 178, pp. 681-702, 2016.

[10] M. Ameri, P. Ahmadi, and S. Khanmohammadi, "Exergy analysis of a 420 MW combined cycle power plant," International Journal of Energy Research, vol. 32, pp. 175-183, 2008.

[11] M. T. Mansouri, P. Ahmadi, A. G. Kaviri, and M. N. M. Jaafar, "Exergetic and economic evaluation of the effect of HRSG configurations on the performance of combined cycle power plants," Energy Conversion and Management, vol. 58, pp. 47-58, 2012.

[12] S. Quoilin, R. Aumann, A. Grill, A. Schuster, V. Lemort, and H. Spliethoff, "Dynamic modeling and optimal control strategy of waste heat recovery Organic Rankine Cycles," Applied Energy, vol. 88, pp. 21832190, 2011.

[13] B. Tashtoush, M. Molhim, and M. Al-Rousan, "Dynamic model of an HVAC system for control analysis," Energy, vol. 30, pp. 1729-1745, 2005.

[14] F. Alobaid, R. Postler, J. Ströhle, B. Epple, and H.-G. Kim, "Modeling and investigation start-up procedures of a combined cycle power plant," Applied Energy, vol. 85, pp. 1173-1189, 2008.

[15] S. Kuravi, J. Trahan, D. Y. Goswami, M. M. Rahman, and E. K. Stefanakos, "Thermal energy storage technologies and systems for concentrating solar power plants," Progress in Energy and Combustion Science, vol. 39, pp. 285-319, 2013.

[16] F. Agyenim, N. Hewitt, P. Eames, and M. Smyth, "A review of materials, heat transfer and phase change problem formulation for latent heat thermal energy storage systems (LHTESS)," Renewable and sustainable energy reviews, vol. 14, pp. 615-628, 2010.

[17] A. Gil, M. Medrano, I. Martorell, A. Lázaro, P. Dolado, B. Zalba, et $a l .$, "State of the art on high temperature thermal energy storage for power generation. Part 1 - Concepts, materials and modellization," Renewable and Sustainable Energy Reviews, vol. 14, pp. 31-55, 2010.

[18] K. Lafdi, O. Mesalhy, and A. Elgafy, "Graphite foams infiltrated with phase change materials as alternative materials for space and terrestrial thermal energy storage applications," Carbon, vol. 46, pp. 159168, 2008.

[19] S. Patankar, Numerical Heat Transfer and Fluid Flow: McGraw Hill, 1980.

[20] P. Verma and S. Singal, "Review of mathematical modeling on latent heat thermal energy storage systems using phase-change material," Renewable and Sustainable Energy Reviews, vol. 12, pp. 999-1031, 2008. [21] R. J. Bass, W. Malalasekera, P. Willmot, and H. K. Versteeg, "The impact of variable demand upon the performance of a combined cycle gas turbine (CCGT) power plant," Energy, vol. 36, pp. 1956-1965, 2011. 